\title{
Uso de aditivos microbianos de inclusão direta para vacas leiteiras no terço médio da lactação
}

\author{
Bello, A.H.C.P. ${ }^{\prime}$; Lage, C.F.A.L. ${ }^{\circledR} ;$ Malacco, V.M.R.M. ${ }^{1}$; Zacaroni, O.F. ${ }^{2}$; Pereira, M.N. ${ }^{2}$ e Reis, R.B. ${ }^{1}$
}

'Escola de Veterinária da Universidade Federal de Minas Gerais, Belo Horizonte, Brasil.

2Universidade Federal de Lavras, Lavras, Brasil.

\section{PaLAVRAS CHAVE ADICIONAIS}

Nutrição animal.

Microrganismo.

Rúmen.

\section{RESUMO}

Quinze vacas Holandês, com $156 \pm 53$ dias em lactação, produção média de leite $31,4 \pm 0,5 \mathrm{~kg} / \mathrm{d}$ e peso corporal médio de $665 \pm 16 \mathrm{~kg}$ foram utilizadas com o objetivo de avaliar o uso de aditivos microbianos na dieta. $O$ delineamento experimental adotado foi o de quadrado latino $3 \times 3$, com cinco repetições. Os tratamentos foram: DFM-B (Ruminobacter amylophilum, Ruminobacter succinogenes, Succinovibro dextrinsolvens, Bacillus cereus, Lactobacillus acidophilus, Enterococus faecium em carbonato de cálcio); DFM-BL (Bactérias e veículo inerte associado a $6 \times 10^{9} / \mathrm{g}$ de células vivas e $2 \times 10^{8} / \mathrm{g}$ de células mortas de Sacharomyces cerevisiae) ou Controle - $10 \mathrm{~g}$ de carbonato de cálcio. Os aditivos foram fornecidos em cápsulas por ingestão forçada duas vezes ao dia. A suplementação de animais em terço médio de lactação com DFM-B ou DFM-BL não alterou o consumo, produção e composição de leite, eficiência alimentar, peso e escore de condição corporal. No entanto, animais suplementados com DFM-B tenderam a ter menor pH ruminal, menor excreção de alantoína na urina, maior Nitrogênio ureico no leite (NUL) e menor digestibilidade da matéria seca. Animais suplementados com DFM-BL tenderam a ter menor contagem de células somáticas no leite e maior tempo de mastigação diária, sugerindo que a suplementação associada de bactérias e leveduras tem maior potencial benéfico do que a utilização de apenas bactérias.

\section{Use of direct fed microbial for mid lactation dairy cows}

\section{SUMMARY}

\section{ADDITIONAL KEYWORDS}

Animal nutrition.

Microorganism.

Rumen.

\section{INFORMATION}

\section{Cronología del artículo.}

Recibido/Received: 23.02.2018

Aceptado/Accepted: 16.06.2018

On-line: 07.04 .2019

Correspondencia a los autores/Contact e-mail:

camilassislage@yahoo.com.br
Fiffeen Holstein cows, with $156 \pm 53$ days in milk, average milk yield of $31.4 \pm 0.5$ $\mathrm{kg} / \mathrm{d}$ and body weight of $665 \pm 16 \mathrm{~kg}$ were used with the objective of evaluating the use of microbial additives in the diet. The experiment was arranged in a $3 \times 3$ Latin square design with five replications. The treatments were: DFM-B (Ruminobacter amylophilum, Ruminobacter succinogenes, Succinovibro dextrinsolvens, Bacillus cereus, Lactobacillus acidophilus, Enterococus faecium in calcium carbonate); DFM-BL (Bacteria and inert vehicle associated with $6 \times 10^{9} / \mathrm{g}$ live cells and $2 \times 10^{8} / \mathrm{g}$ dead cells of Sacharomyces cerevisiae) or Control - $10 \mathrm{~g}$ of calcium carbonate. The additives were supplied in capsules by forced ingestion twice a day. Supplementation of animals in the middle lactation with DFM-B or DFM-BL did not alter dry matter intake, milk production and composition, feed efficiency, body weight and body condition score. However, animals supplemented with DFM-B tended to have lower ruminal $\mathrm{pH}$, lower alanine excretion, higher nitrogênio uréico no leite (MUN) and lower digestibility of dry matter. Animals supplemented with DFM-BL tended to have lower somatic cell count in milk and increased daily mastication time, suggesting that the associated supplementation of bacteria and yeasts has greater beneficial potential than the use of only bacteria.

\section{INTRODUÇÃO}

A utilização de aditivos microbianos de inclusão direta (DFM) tem sido estudada com o intuito de manipular as características de fermentação ruminal, objetivando melhorar o desempenho e a saúde das vacas leiteiras (Luan et al. 2015, p. 6423). A demanda nutricional de vacas leiteiras de alta produção resulta em dietas com alta inclusão de grãos, o que é um desafio à microflora ruminal. O modo de ação dos DFM proveniente de fungos e bactérias ainda não é bem estabelecido, mas incluem mudanças no padrão de fermentação ruminal, maior estabilidade do $\mathrm{pH}$ ruminal, maior extensão de digestão das fibras, aumento no consumo de matéria seca (CMS) e consequente aumento na pro- 
dução de leite (Nocek et al. 2003; Nocek \& Kautz 2006; Philippeau et al. 2017).

Produtos DFM proveniente de fungos foram estudados em maior extensão para vacas leiteiras do que produtos DFM proveniente de bactérias (Raeth-Knight, Linn \& Jung 2007, p. 1803) e os principais benefícios da inclusão de leveduras na dieta dos animais incluem o aumento no número total de bactérias, aumento da velocidade de crescimento de bactérias celulolíticas, melhor colonização das partículas de alimentos, além de maior estímulo para o crescimento das bactérias utilizadoras de lactato (Chaucheyras-Durand, Walker \& Bach 2008, p. 8). Em conjunto, esses efeitos culminam em maior saúde ruminal, menor variação de $\mathrm{pH}$ e aumento da digestibilidade da fibra no rúmen, o que resultaria em maior digestão da matéria orgânica em todo o trato digestivo (Desnoyers et al. 2009, p. 1620). $\mathrm{O}$ efeito positivo das leveduras sobre a digestibilidade da fibra seria mais pronunciado em dietas ou sistemas de alimentação capazes de comprometer a atividade de microrganismo celulolíticos, como em dietas com alta inclusão de alimentos concentrados (Chiquette et al. 2015; Uyeno et al. 2017).

A utilização de bactérias como DFM foi negligenciada pelo fato da maioria delas estarem presentes no rúmen (Philippeau et al. 2017, p. 2638). Maior interesse pelo seu uso se iniciou a partir da percepção de potencial para alterar a fermentação ruminal e as características da população microbiana (Ghorbani et al. 2002; Elghandour et al. 2015). O fornecimento de DFM com microrganismos produtores e utilizadores de ácido lático possibilitaria alterar o ambiente ruminal com o fornecimento constante desse ácido, que manteria a população de microrganismos utilizadores metabolicamente ativa (Nocek et al. 2003, p. 331; Philippeau et al. 2017, p. 2638). Logo, em momentos de maior produção de ácido lático no rúmen ocorreria seu maior sequestro por esses microrganismos evitando quedas acentuadas do $\mathrm{pH}$.

A combinação de diferentes DFM poderia aumentar efeitos benéficos para a saúde do rúmen comparado a cepas individuais pelos efeitos sinérgicos (Collado, Meriluoto \& Salminen 2007, p. 71). Foi hipotetizado, que a associação entre suplementação com aditivos à base de bactérias ruminais e leveduras vivas e mortas, poderia resultar em melhor saúde ruminal, o que favoreceria o processo fermentativo, digestão da fibra e consequentemente aumentaria a produtividade das vacas em lactação.

O objetivo deste estudo foi avaliar a inclusão de aditivos à base de bactérias ruminais ou bactérias ruminais associadas a leveduras em dietas de vacas em lactação, sobre a fermentação ruminal, produção e composição do leite e comportamento alimentar.

\section{MATERIAL E MÉTODOS}

Todos os procedimentos realizados seguiram as orientações do comitê de ética na experimentação animal (Pacheco, Saad \& Trevizan 2012, pp. 260-266) e da Universidade Federal de Minas Gerais.
Foram utilizadas quinze vacas da raça Holandês, com $156 \pm 53$ dias em lactação, produção de leite média de $31,4 \pm 0,5 \mathrm{~kg} / \mathrm{d}$ e peso corporal médio de $665 \pm 16 \mathrm{~kg}$ no início do experimento. O delineamento experimental adotado foi o de quadrado latino $3 \times 3$, com cinco repetições. Os períodos experimentais tiveram duração de 35 dias cada, sendo 28 dias de adaptação dos animais às dietas e sete dias de coletas e avaliações.

As vacas foram distribuídas aleatoriamente a cada um dos tratamentos: Controle, em que os animais recebiam $10 \mathrm{~g}$ de cabornato de cálcio; DFM-B, em que os animais recebiam $10 \mathrm{~g}$ de suplemento de bactérias composto por Ruminobacter amylophilum, Ruminobacter succinogenes, Succinovibro dextrin solvens, Bacillus cereus, Lactobacillus acidophilus, Enterococus faecium em carbonato de cálcio (Imeve Indústria de Medicamentos Veterinários Ltda, Jaboticabal, SP); ou DFM-BL, em que os animais recebiam $10 \mathrm{~g}$ de suplemento das bactérias e veículo inerte associado a $6 \times 10^{\circ} / \mathrm{g}$ de células vivas e $2 \times 10^{8} / \mathrm{g}$ de células mortas de Sacharomyces cerevisiae (Imeve Indústria de Medicamentos Veterinários Ltda, Jaboticabal, SP). Os aditivos foram fornecidos em cápsulas por ingestão forçada duas vezes ao dia, após o fornecimento da alimentação às $6 \mathrm{~h}$ e às $15 \mathrm{~h}$.

Para comprovar as especificações do produto, foi realizada a contagem da população de leveduras por meio do plaqueamento em superfície. Utilizou-se o meio YEPG contendo: 0,3\% de extrato de levedura (Merck); 0,3\% de extrato de malte (Merck); 0,5\% de peptona (Himedia); 1,0\% de glicose (Merck); 2,0\% de ágar (Merck); adicionados a $1000 \mathrm{ml}$ de água contendo $100 \mathrm{mg}$ cloranfenicol (Sigma, St. Louis, USA). As placas foram incubadas a $28^{\circ} \mathrm{C}$ por $72 \mathrm{~h}$. Após a incubação foi realizada diluição serial garantindo entre 30 e 300 colônias para realização da contagem, sendo o resultado dado em unidades formadoras de colônia (UFC)/g de produto. O produto se encontrava dentro das especificações do fabricante.

Durante todo o período experimental as vacas foram alimentadas individualmente em confinamento total do tipo tie stall com camas de areia. As vacas foram ordenhadas duas vezes ao dia, às $05 \mathrm{~h}$ e às $13 \mathrm{~h}$. As dietas foram formuladas para atender os requisitos nutricionais dos animais (NRC 2001) e estão demonstradas na Tabela I.

A dieta total (TMR) foi oferecida aos animais duas vezes ao dia, às $06 \mathrm{~h}$ e às $15 \mathrm{~h}$. Os ingredientes da dieta foram misturados em vagão misturador a TMR foi fornecida em quantidade suficiente para proporcionar no mínimo $5 \%$ do oferecido como sobra diária. A proporção de silagem na dieta foi ajustada semanalmente pela variação no teor de matéria seca (MS), determinado por secagem em aparelho Koster (Koster Moisture Tester, Medina, EUA) por 60min.

As dietas oferecidas e as sobras foram mensuradas diariamente para determinar o consumo de matéria seca (CMS). Do $28^{\circ}$ ao $32^{\circ}$ dia de cada período experimental amostras de cada alimento e das sobras de cada animal foram coletadas diariamente e congeladas. Uma amostra composta dos alimentos e uma das sobras foi formada para cada período por mistura de quantidades idênticas de matéria natural. 
As amostras foram pré-secas em estufa ventilada a $55^{\circ} \mathrm{C}$ por 72 horas e trituradas em moinho do tipo Thomas-Willey em peneira com crivos de $1 \mathrm{~mm}$. Uma sub-amostra foi destinada para determinação do teor de matéria seca (MS), realizada por desidratação em estufa a $105^{\circ} \mathrm{C}$ por $24 \mathrm{~h}$. As amostras foram analisadas para: Proteína bruta usando o método Kjeldahl (AOAC International, 2012, método 955.04), extrato etéreo (AOAC International, 2012, método 920.39) e cinzas (AOAC International, 2012; método 942.05). A FDN foi determinada de acordo com Van Soest, Robertson \& Lewis (1991, p. 3586). Os carboidratos não fibrosos foram calculados pela fórmula: $\mathrm{CNF}=100$ - (PB+EE+Cinzas+FDN) (NRC 2001). A composição da dieta em nutrientes e ingredientes está exposta na Tabela I.

Amostras de leite foram coletadas de oito ordenhas consecutivas do $28^{\circ}$ a $31^{\circ}$ dias de período experimental para determinação de teores de proteína, gordura, lactose, sólidos totais, nitrogênio uréico (NUL) e contagem de células somáticas (CCS). As amostras foram coletadas em frascos contendo 2-bromo-2-nitropropano1-3-diol e analisadas por infravermelho em aparelho Bentley 2000 (Bentley 2000. Bentley Instruments Inc., Chaska, MN).

A secreção diária de energia no leite foi calculada pela equação do NRC (2001): [(0,0929 x \% gordura) + $(0,0547 \times \%$ de proteína $)+(0,0395 \times \%$ de lactose $)] x$ $\mathrm{kg}$ de leite. A produção de leite corrigida para energia (Leite E) foi calculada pela equação: Leite E= EnLeite $/ 0,70$, assumindo que o conteúdo de energia em leite com 3,7\% de gordura, 3,2\% de proteína e 4,6\% de lactose é 0,70 Mcal $/ \mathrm{kg}$.

A produção de leite corrigida para $4 \%$ de gordura foi calculada pela equação: Leite $4 \%=(0,4+15 \times \%$ de gordura/100) x kg de leite. As eficiências alimentares foram calculadas: Eficiência 1 pela relação entre a produção de leite e o CMS e a Eficiência 2 pela relação entre Leite E e o CMS.

No $34^{\circ}$ dia de cada período experimental o peso vivo dos animais foi mensurado após a ordenha da manhã, por pesagem em balança digital (Toledo MGR2000, São Bernardo, Brazil). Escore de condição corporal foi avaliado visualmente em escala de 1 a 5 , sendo 1 representativo de uma vaca de baixo escore de condição corporal e 5 representativo de uma vaca super condicionada (Wildman et al. 1982, p. 496-498). A condição corporal foi avaliada por três avaliadores independentes e o escore médio de cada vaca foi utilizado para descrição das unidades experimentais.

As digestibilidades aparentes no trato digestivo total da matéria seca (MS), da matéria orgânica (MO), da FDN e da MO não-FDN foram determinadas por coleta total de fezes realizada por oito horas ininterruptas entre o $31^{\circ}$ e $33^{\circ}$ dias de cada período experimental. A coleta de fezes a cada dia foi iniciada com oito horas de atraso com relação ao dia anterior, visando obter amostragem representativa das 24 horas do dia sem causar distúrbio no consumo de alimentos e na produção de leite dos animais.

As fezes foram continuamente congeladas durante o período de coleta e uma amostra composta foi for-

Tabela I. Composição das dietas oferecidas (ingredientes) e das consumidas (nutrientes), de vacas em lactação suplementadas com bactérias (DFM-B), bactérias e leveduras (DFM-BL) ou controle (Composition of the diets offered (ingredients) and consumed (nutrients), lactating dairy cows supplemented with bacteria (DFM-B), bacteria and yeasts (DFM-BL) or control)

\begin{tabular}{lccc}
\hline Item (\% Matéria seca) & Controle & DFM-B & DFM-BL \\
\hline Silagem de milho & 27,7 & 27,7 & 27,7 \\
Silagem de sorgo & 18,1 & 18,1 & 18,1 \\
Silagem de tifton & 3,3 & 3,3 & 3,3 \\
Farelo de soja & 20,2 & 20,2 & 20,2 \\
Milho reidratado e ensilado & 9,3 & 9,3 & 9,3 \\
Milho moído fino & 11,9 & 11,9 & 11,9 \\
Polpa de citros & 8,2 & 8,2 & 8,2 \\
Minerais e vitaminas ${ }^{1}$ & 1,3 & 1,3 & 1,3 \\
Proteína bruta & 18,2 & 18,1 & 18,1 \\
Fibra em detergente neutro (FDN) & 34,4 & 34,1 \\
FDN oriundo de forragem & 33,7 & 27,8 & 27,6 \\
Extrato etéreo & 27,3 & 3,8 & 3,8 \\
Cinzas & 3,8 & 5,1 & 5,1 \\
Carboidratos não-fibrosos & & 38,7 & 3 \\
\hline
\end{tabular}

${ }^{1}$ Premix $=55 \%$ calcário calcítico, $15 \% \mathrm{NaCl}$ e $30 \%$ mineral comercial $(18,5 \% \mathrm{Ca} ; 15,0 \% \mathrm{P} ; 3,0 \% \mathrm{Mg} ; 3,0 \% \mathrm{~S} ; 240 \mathrm{ppm}$ Co; $3.000 \mathrm{ppm}$ Cu;

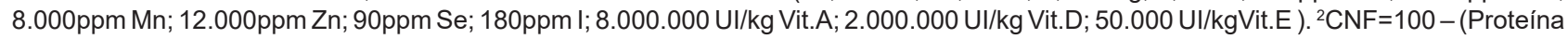
bruta + Extrato etéreo + FDN + Cinzas). 
Tabela II. Consumo de matéria seca (CMS), produção e composição de leite, contagem de células somáticas (CCS), nitrogênio ureico no leite (NUL) e eficiência alimentar de vacas em lactação suplementadas com bactérias (DFM-B), bactérias e leveduras (DFM-BL) ou controle (Milk production and composition, somatic cell counts (CCS), urea nitrogen in milk (NUL) in lactation cows fed diets supplemented with bacteria (DFM-B), bacteria and yeasts (DFM))

\begin{tabular}{|c|c|c|c|c|c|c|c|}
\hline Item (kg/d) & Controle & DFM-B & DFM-BL & EPM $^{1}$ & P Trat $^{2}$ & $\mathrm{PC} 1^{2}$ & $\mathrm{PC}^{2}$ \\
\hline $\mathrm{CMS}^{3}$ & 20,50 & 20,20 & 20,70 & 0,37 & 0,61 & 0,51 & 0,75 \\
\hline Leite & 31,10 & 31,30 & 32,00 & 0,70 & 0,66 & 0,87 & 0,39 \\
\hline Leite $4 \%{ }^{4}$ & 28,70 & 28,70 & 29,50 & 0,73 & 0,70 & 0,99 & 0,46 \\
\hline Leite $\mathrm{E}^{5}$ & 30,50 & 30,60 & 31,30 & 0,79 & 0,77 & 0,99 & 0,53 \\
\hline Gordura & 1,08 & 1,08 & 1,11 & 0,03 & 0,75 & 0,93 & 0,55 \\
\hline Proteína & 1,03 & 1,03 & 1,04 & 0,02 & 0,95 & 0,88 & 0,75 \\
\hline Lactose & 1,43 & 1,44 & 1,48 & 0,03 & 0,64 & 0,96 & 0,40 \\
\hline Sólidos totais & 3,86 & 3,86 & 3,95 & 0,09 & 0,75 & 0,97 & 0,51 \\
\hline \multicolumn{8}{|l|}{$\%$} \\
\hline Gordura & 3,49 & 3,50 & 3,48 & 0,07 & 0,98 & 0,94 & 0,89 \\
\hline Proteína & 3,32 & 3,34 & 3,28 & 0,02 & 0,34 & 0,59 & 0,35 \\
\hline Lactose & 4,61 & 4,59 & 4,61 & 0,01 & 0,69 & 0,41 & 0,82 \\
\hline Sólidos totais & 12,41 & 12,41 & 12,35 & 0,10 & 0,87 & 0,98 & 0,66 \\
\hline \multicolumn{8}{|l|}{1 a 9} \\
\hline CCS Linear ${ }^{6}$ & 4,21 & 3,82 & 3,71 & 0,02 & 0,29 & 0,24 & 0,14 \\
\hline \multicolumn{8}{|l|}{$\mathrm{mg} / \mathrm{dL}$} \\
\hline $\mathrm{NUL}^{7}$ & 16,60 & 17,30 & 16,10 & 0,26 & 0,01 & 0,10 & 0,12 \\
\hline Efic $1^{8}$ & 1,52 & 1,55 & 1,55 & 0,04 & 0,89 & 0,65 & 0,72 \\
\hline Efic $2^{9}$ & 1,49 & 1,52 & 1,51 & 0,04 & 0,92 & 0,69 & 0,79 \\
\hline \multicolumn{8}{|l|}{$\mathrm{kg}$} \\
\hline Peso vivo & 662 & 663 & 670 & 4,50 & 0,37 & 0,95 & 0,22 \\
\hline \multicolumn{8}{|l|}{1 a 5} \\
\hline Condição corporal & 3,34 & 3,36 & 3,40 & 0,02 & 0,53 & 0,88 & 0,75 \\
\hline
\end{tabular}

${ }^{1} \mathrm{EPM}=$ Erro padrão das médias. ${ }^{2} \mathrm{P}=$ Valor de probabilidade para os efeitos de tratamento, C1=Controle vs. DFM-B e C2=Controle vs. DFM-BL. ${ }^{3}$ Consumo de matéria seca. ${ }^{4}$ Leite ajustado para $4 \%$ de gordura. ${ }^{5}$ Leite ajustado para energia. ${ }^{6} \mathrm{Contagem}$ de células somáticas linear. ${ }^{7}$ Nitrogênio uréico do leite. ${ }^{8}$ Eficiência 1=Produção de leite/CMS. ${ }^{9}$ Eficiência 2=Leite E/CMS.

mada para cada vaca por período. As amostras compostas de fezes foram desidratadas e o teor de FDN e cinzas foram determinados como descrito anteriormente. $\mathrm{O}$ consumo diário de matéria orgânica digestível (CMOD) foi calculado para estimar o consumo de energia.

Simultaneamente à coleta de fezes, foi realizada coleta total de urina. Ao volume de urina coletado foram imediatamente adicionados $10 \%$ de ácido sulfúrico a $20 \%$ e a amostra foi armazenada a $4^{\circ} \mathrm{C}$. Uma amostra composta foi formada para cada vaca por período. As amostras compostas foram diluídas com solução de 4\% de ácido sulfúrico na proporção de uma parte de solução de ácido sulfúrico para três partes de urina e congeladas a $-20^{\circ} \mathrm{C}$ até a realização das análises. $\mathrm{O}$ teor de alantoína foi mensurado segundo Chen e Gomes (1992 p. 17-19).

Do $31^{\circ}$ ao $33^{\circ}$ dia de cada período experimental foi avaliada visualmente a atividade bucal de cada animal a cada 5 minutos. As atividades bucais consideradas foram: ingestão de alimento, ingestão de água, rumi- nação e ócio. O tempo de mastigação em minutos por dia foi definido como a soma dos tempos de ingestão de alimento e de ruminação. Os tempos de mastigação, ingestão e ruminação por CMS foram calculados utilizando-se o consumo mensurado nos dias da avaliação.

No $35^{\circ}$ de cada período experimental amostras de fluido ruminal foram obtidas utilizando sonda flexível oro-gástricas com auxílio de uma bomba de sucção a vácuo acoplada a um balão Kitassato. As amostras foram obtidas $11,6 \pm 0,3$ horas após o fornecimento matinal de alimentos e ao acaso dentro de quadrado. $\mathrm{O}$ pH ruminal foi mensurado imediatamente após a coleta.

As variáveis foram analisadas pelo procedimento GLM do SAS (2001) com o seguinte modelo:

Yijklm=m $+\mathrm{Qi}+\mathrm{Vj}(\mathrm{i})+\mathrm{Pk}+\mathrm{Tl}+$ eijkl.

Em que: $\mathrm{m}=$ média geral, $\mathrm{Qi}=$ efeito de quadrado $(i=1$ a 5$), V j(i)=$ efeito de vaca dentro de quadrado $(j=1$ a 15), $\mathrm{Pk}=$ efeito de período ( $\mathrm{k}=1$ a 3$), \mathrm{Tl}=$ efeito de tratamento (l=Cont, Bact, Bact+Lev), eijkl=erro residual, as- 
sumido independente e identicamente distribuído em uma distribuição normal com média zero e variância $\mathrm{s}^{2}$.

Dois contrastes pré-planejados compararam tratamentos: C1=Cont vs. Bact, C2=Cont vs. Bact+Lev. Valores de probabilidade abaixo de 0,05 foram considerados como significativos e valores $>0,05$ e $\leq 0,15$ foram aceitos como tendência.

\section{RESULTADOS E DISCUSSÃO}

A suplementação com DFM-B ou DFM-BL não afetou o consumo de matéria seca (Tabela II). As dietas oferecidas foram semelhantes quanto aos teores nutricionais, pois o intuito do presente estudo foi elucidar, exclusivamente, os efeitos do uso dos aditivos. A ausência de diferença em CMS resultou em consumo semelhante de nutrientes entre os grupos.

A ingestão de matéria seca em vacas está relacionada diretamente ao conteúdo de parede celular e a densidade energética da dieta (Forbes 1995). Uma vez que a dieta era a mesma, a quantidade de FDN e carboidratos não fibrosos semelhantes, a diferenças no consumo de matéria seca entre as dietas experimentais estariam relacionado a um menor tempo de retenção da dieta por uma maior digestibilidade, resultado de melhora da fermentação ruminal que pode ser esperado em dietas com inclusão de DFM.

A literatura é inconsistente com relação a resposta em CMS devido a suplementação com DFM, com relatos de aumento (Nocek \& Kautz 2006; Desnoyers et al. 2009; Moallem et al. 2009) ou sem alteração na mesma (Bach, Iglesias \& Devant 2007; Ferrareto, Shaver \& Bertis 2012; Luan et al. 2015). Não ocorreram diferenças em nenhum parâmetro de produção e composição de leite entre os tratamentos (Tabela II). Esse resultado acompanha a não diferença em consumo de matéria seca.

Nocek et al. (2006, p. 262-263) suplementando DFM bacteriano para vacas no pré e pós-parto encontraram diferenças em consumo e produção de leite, que foram atribuídas a uma maior estabilidade ruminal, maior $\mathrm{pH}$ e consequentemente maior digestibilidade da fibra, que garantiu maior aporte de nutrientes e maior produção de leite. No presente estudo a suplementação com bactérias ou levedura associada com bactérias parece não ter sido suficiente para causar mudanças significativas no ambiente ruminal que aumentassem a eficiência alimentar.

Outros trabalhos com DFM bacteriana ou de leveduras também não encontraram resultados positivos em produção de leite (Swartz et al. 1994; Wohlt, Corcione \& Zajac 1998). Nocek et al. (2003) e Nocek \& Kautz (2006) encontraram respostas em CMS e produção de leite em animais que foram suplementados com bactéria associada a leveduras ou apenas bactérias respectivamente. Porém, esses trabalhos foram feitos em animais durante o período de transição.

Raeth-Knight, Linn \& Jung (2007, p.1806) não encontraram resultados em CMS e produção de leite quando avaliaram inclusão de DFD bacteriano em animais no terço médio da lactação. É importante ressaltar que os animais utilizados nesse experimento apresentavam, em media, 156 \pm 53 dias em lactação (DEL). Animais no período de transição são mais susceptíveis a alterações no $\mathrm{pH}$ ruminal devido a uma não adaptação a dietas com altos teores de carboidratos fermentáveis (Hayirli et al. 2002, p. 3438). Essa oscilação de $\mathrm{pH}$ pode afetar o consumo dos animais e medidas que visam regular ambiente ruminal nessa fase podem ter maiores efeitos em consumo e desempenho.

Não houve diferença em eficiência alimentar e mudanças em peso e escore de condição corporal entre os diferentes tratamentos (Tabela II), o que está em consonância aos demais resultados de consumo e produção de leite.

Houve uma tendência $(\mathrm{P}=0,14)$ de redução na contagem de células somáticas (CCS) do leite quando leveduras foram suplementadas (Tabela II), sugerindo que houve efeito do DFM sobre a imunidade. Leveduras e bactérias podem se ligar a bactérias enteropatogênicas nos intestinos, estimular células do sistema imunológico e desencadear resposta de defesa em outras mucosas do corpo, além daquelas em que ocorreu o estímulo inicial. Esse mecanismo de migração de células para outros tecidos é conhecido como sistema imune comum de mucosas (Krehbiel et al. 2003). Alzahal et al. (2014) não encontraram nenhum efeito da suplementação com levedura sob parâmetros de saúde e incidência de doenças. Estudos que avaliam o efeito da suplementação com DFM sob parâmetros de saúde são escassos e mais estudos devem ser feitos para melhor entendimento.

Houve tendência $(P=0,10)$ de aumento no teor de NUL nos animais que receberam DFM-B (Tabela II). Esse achado pode estar associado a uma maior atividade proteolítica pelas bactérias no rúmen, sem utilização concomitante desse nitrogênio, induzindo aumento na perda de amônia ruminal. Já a associação de bactérias com leveduras tendeu a reduzir o teor de NUL $(P=0,12)$. De acordo com Chaucheyras-Durand \& Fonty (2002) a adição de formas ativas de leveduras vivas pode melhorar a colonização de partículas de alimentos e acelerar o crescimento de bactérias, principalmente celulolíticas.

A suplementação com DFM-BL aumentou o tempo diário de mastigação $(\mathrm{P}=0,02)$ e tendeu a aumentar a mastigação por unidade de CMS $(\mathrm{P}=0,06)$ (Tabela III). A resposta em atividade de mastigação foi induzida por aumento no tempo de ingestão, sendo a resposta em ruminação menos evidente.

Independente do tratamento, o pH encontrado nas avaliações realizadas $11,6 \pm 0,3$ horas após o fornecimento foi menor do que os encontrados na literatura para horários similares de coleta (Tabela III). Os animais no presente estudo estavam em acidose subclínica, uma vez que apresentaram $\mathrm{pH}$ ruminal igual ou inferior a 5,5 no momento da amostragem. Segundo Marie Krause \& Oetzel (2006) pH ruminal $\leq 5,5$ são indicativos de acidose subclínica.

O fornecimento de dietas ricas em carboidratos rapidamente fermentáveis melhora o desempenho dos animais, mas também aumenta a chance de acidose 


\begin{tabular}{|c|c|c|c|c|c|c|c|}
\hline Item & Controle & DFM-B & DFM-BL & EPM1 & P Trat $^{2}$ & $P \mathrm{C}^{2}$ & $\mathrm{P} \mathrm{C}^{2}$ \\
\hline \multicolumn{8}{|c|}{$\min / \mathrm{d}$} \\
\hline Ingestão & 345 & 360 & 376 & 15,20 & 0,36 & 0,47 & 0,15 \\
\hline Ruminação & 461 & 442 & 490 & 15,90 & 0,12 & 0,41 & 0,21 \\
\hline Mastigação & 806 & 803 & 866 & 16,60 & 0,02 & 0,89 & 0,02 \\
\hline \multicolumn{8}{|c|}{$\mathrm{min} / \mathrm{kg} \mathrm{CMS}$} \\
\hline Ingestão & 17,10 & 18,00 & 18,40 & 0,77 & 0,49 & 0,43 & 0,24 \\
\hline Ruminação & 22,80 & 22,10 & 24,00 & 0,83 & 0,29 & 0,52 & 0,35 \\
\hline Mastigação & 39,90 & 40,00 & 42,30 & 0,88 & 0,11 & 0,93 & 0,06 \\
\hline \multicolumn{8}{|c|}{ mmoles/d } \\
\hline Alantoína & 305 & 257 & 284 & 19,90 & 0,24 & 0,15 & 0,46 \\
\hline $\mathrm{pH}$ ruminal & 5,50 & 5,34 & 5,46 & 0,06 & 0,17 & 0,08 & 0,68 \\
\hline
\end{tabular}

ruminal subclínica. Os animais do presente experimento eram animais de alta produção de leite que foram desafiados com uma dieta rica em grãos para que possíveis diferenças entre os tratamentos pudessem ser evidenciadas.

Outro fator que possivelmente predispôs os animais a uma acidose subclínica foi o estresse térmico uma vez que o experimento foi conduzido durante o verão. Animais em estresse térmico podem ter menor concentração de bicabornato na saliva (Schneider et al. 1984) e menor tempo de ruminação, o que reduz a produção de saliva (Soriani, Panela \& Calamari 2013).

Houve tendência de queda de $\mathrm{pH}$ no grupo DFM-B em relação ao grupo controle $(\mathrm{P}=0,08)$ (Tabela III). Owens et al. (1998) sugeriram que a suplementação de ácido láctico na dieta ou a inclusão de algum ingrediente com alto teor desse ácido poderia melhorar a habilidade do rúmen em adaptar-se às condições que levariam ao aumento rápido da concentração de ácido láctico. Isso aconteceria pelo estabelecimento da microbiota utilizadora de ácido lático que ajudariam a regular o pH. O aumento da produção de ácido lático não foi acompanhado de estabelecimento da microbiota utilizadora de ácido lático, o que pode ter resultado em pH mais baixo do que nos animais do grupo controle.

A inclusão de leveduras junto a suplementação de bactérias teve um efeito regulador no $\mathrm{pH}$, que se manteve igual ao grupo controle. Bach, Iglesias \& Devant (2007), observaram que o pH ruminal médio, em vacas em lactação suplementadas com $5 \mathrm{~g}$ de leveduras vivas (S. cerevisiae cepa CNCM I-1077), foi de 6,02, em comparação à média de 5,51 nos animais não suplementados. A inclusão de leveduras no presente trabalho não foi suficiente para melhorar o ambiente ruminal. Mais estudos com novas doses devem ser realizados para mensurar esse efeito nas condições avaliadas.

Tabela IV. Digestibilidade aparente no trato digestivo total da matéria seca (DMS), da matéria orgânica (DMO), da fibra em detergente neutro (DFDN), e da matéria orgânica não FDN (DMÓnFDN) e consumo de matéria orgânica digestível (CMOD) de vacas em lactação suplementadas com bactérias (DFM-B), bactérias e leveduras (DFM-BL) ou controle (Apparent digestibility in the total digestive tract of dry matter (DMS), organic matter (DMO), neutral detergent fiber (DFDN), and organic matter non-NDF (DMOnFDN) and consumption of digestible organic matter of lactating cows supplemented with bacteria (DFM-B), bacteria and yeasts (DFM-BL) or control).

\begin{tabular}{llllllll}
\hline Item & Controle & DFM-B & DFM-BL & EPM $^{1}$ & P Trat $^{2}$ & $\mathrm{PC}^{2}$ & $\mathrm{P} \mathrm{C2}^{2}$ \\
\hline DMS & 66,20 & 64,40 & 64,80 & 0,84 & 0,31 & 0,15 & 0,25 \\
DMO & 69,20 & 67,60 & 68,10 & 0,08 & 0,39 & 0,18 & 0,38 \\
DFDN & 26,50 & 23,90 & 25,50 & 3,25 & 0,84 & 0,56 & 0,81 \\
DMOnFDN & 93,40 & 93,40 & 92,20 & 0,83 & 0,51 & 0,95 & 0,30 \\
kg/d & & & & & & & \\
CMOD & 13,60 & 13,10 & 13,60 & 0,31 & 0,39 & 0,21 & 0,87 \\
\hline
\end{tabular}

${ }^{1}$ EPM=Erro padrão das médias.

${ }^{2} P=$ Valor de probabilidade para os efeitos de tratamento, $\mathrm{C} 1=$ Controle vs. DFM-B e C2=Controle vs. DFM-BL 
Houve tendência $(\mathrm{P}=0,15)$ de redução da produção de alantoína (Tabela III) no grupo DFM-B. A multiplicação microbiana de alguns tipos de bactérias é prejudicado em condições de $\mathrm{pH} \leq 5,5$, mesmo que a atividade metabólica das espécies restantes continue alto (Marie Krause \& Oetzel 2006). Essa redução na multiplicação de algumas espécies reduz a produção total de proteína microbiana e consequentemente os resultados de alantoína. Esse resultado está de acordo com os resultados de NUL encontrados, uma vez que menor multiplicação de microrganismos resultaria em menor utilização de compostos nitrogenados no rúmen e maior perda de nitrogênio como uréia no leite.

Houve tendência $(P=0,15)$ de queda na digestibilidade da MS no tratamento DFM-B (Tabela IV). A queda induzida por este tratamento no $\mathrm{pH}$ ruminal pode estar relacionado a este achado, sendo coerente à queda numérica observada na digestibilidade da FDN. Bactérias fibrolíticas são reconhecidamente inibidas por baixo $\mathrm{pH}$. Apesar da tendência de menor digestibilidade, não houve efeito detectável de tratamento sobre o consumo diário de energia, mensurado pelo CMOD.

\section{CONCLUSÃO}

No presente trabalho, os animais suplementados com DFM que incluíam bactérias e leveduras tenderam a ter uma melhor saúde de glândula mamária e dispenderam maior tempo diário em mastigação, o que, apesar de no presente trabalho não ter afetado o $\mathrm{pH}$ de rúmen, tem potencial para aumentar a produção de saliva e auxiliar no tamponamento ruminal. Em conjunto, esses dados sugerem que a suplementação associada de bactérias e leveduras tem maior potencial benéfico do que a utilização de apenas bactérias.

Mais estudos devem ser realizados, incluindo diferentes doses e cepas de aditivos microbianos de inclusão direta com o objetivo de avaliar os efeitos benéficos desses aditivos sob a saúde ruminal, de glândula mamária e sob a eficiência de utilização do nitrogênio.

\section{BIBLIOGRAFIA}

AlZahal, O, Dionissopoulos, L, Laarman, AH, Walker, N \& McBride, BW 2014, 'Active dry Saccharomyces cerevisiae can alleviate the effect of subacute ruminal acidosis in lactating dairy cows', Journal of Dairy Science, vol. 97, pp. 7751-63.

Bach, A, Iglesias, C \& Devant, M 2007, 'Daily rumen pH pattern of loose-housed dairy cattle as affected by feeding pattern and live yeast supplementation', Animal Feed Science and Technology, vol. 136, pp. 146-53.

Chaucheyras-Durand, F \& Fonty, G 2002, 'Influence of a probiotic yeast (Saccharomyces cerevisiae CNCM I-1077) on microbial colonization and fermentations in the rumen of newborn lambs', Microbial Ecology in Health and Disease, vol. 14, pp. 30-6.

Chaucheyras-Durand, F, Walker, ND \& Bach, A 2008, 'Effects of active dry yeasts on the rumen microbial ecosystem: Past, present and future', Animal Feed Science and Technology, vol. 145, pp. 5-26.

Chen, XB, \& Gomes, MJ 1995, 'Estimation of microbial protein supply to sheep and cattle based on urinary excretion of purine derivativesan overview of the technical details', International Feed Resources Unit, pp. 1-19.

Chiquette, J, Lagrost, J, Girard, CL, Talbot, G, Li, S, Plaizier, JC \& Hindrichsen, IK 2015, 'Efficacy of the direct-fed microbial Enterococcus faecium alone or in combination with Saccharomyces cerevisiae or Lactococcus lactis during induced subacute ruminal acidosis', Journal of Dairy Science, vol. 98, pp. 190-203.

Collado, MC, Meriluoto, J \& Salminen, S 2007, 'Measurement of aggregation properties between probiotics and pathogens: in vitro evaluation of different methods', Journal of Microbiological Methods, vol. 71, pp. 71-4.

Desnoyers, M, Giger-Reverdin, S, Bertin, G, Duvaux-Ponter, C \& Sauvant, D 2009, 'Meta-analysis of the influence of Saccharomyces cerevisiae supplementation on ruminal parameters and milk production of ruminants', Journal of Dairy Science, vol. 92, pp. 1620-32.

Elghandour, MM, Salem, AZ, Castañeda, JSM, Camacho, LM, Kholif, AE \& Chagoyán, JCV 2015, 'Direct-fed microbes: A tool for improving the utilization of low quality roughages in ruminants', Journal of Integrative Agriculture, vol. 14 pp. 526-33.

Ferraretto, LF, Shaver, RD \& Bertics, SJ 2012, 'Effect of dietary supplementation with live-cell yeast at two dosages on lactation performance, ruminal fermentation, and total-tract nutrient digestibility in dairy cows', Journal of Dairy Science, vol. 95, pp. 4017-28.

Forbes, JM 1995, Voluntary food intake and diet selection in farm animals, Cabi.

Ghorbani, GR, Morgavi, DP, Beauchemin, KA \& Leedle, JAZ 2002, 'Effects of bacterial direct-fed microbials on ruminal fermentation, blood variables, and the microbial populations of feedlot cattle', Journal of Animal Science, vol. 80, pp. 1977-85.

Hayirli, A, Grummer, RR, Nordheim, EV \& Crump, PM 2002, 'Animal and dietary factors affecting feed intake during the prefresh transition period in Holsteins', Journal of Dairy Science, vol. 85, pp. 3430-43.

Krause, KM \& Oetzel, GR 2006, 'Understanding and preventing subacute ruminal acidosis in dairy herds: A review', Animal Feed Science and Technology, vol. 126, pp. 215-36.

Krehbiel, CR, Rust, SR, Zhang, G \& Gilliland, SE 2003, 'Bacterial directfed microbials in ruminant diets: Performance response and mode of action', Journal of Animal Science, vol. 81, pp. 120-32.

Luan, S, Duersteler, M, Galbraith, EA \& Cardoso, FC 2015, 'Effects of direct-fed Bacillus pumilus 8G-134 on feed intake, milk yield, milk composition, feed conversion, and health condition of pre-and postpartum Holstein cows', Journal of Dairy Science, vol. 98, pp. 6423-32.

Moallem, U, Lehrer, H, Livshitz, L, Zachut, M \& Yakoby, S 2009, 'The effects of live yeast supplementation to dairy cows during the hot season on production, feed efficiency, and digestibility', Journal of Dairy Science, vol. 92, pp. 343-51.

Nocek, JE \& Kautz, WP 2006, 'Direct-fed microbial supplementation on ruminal digestion, health, and performance of pre-and postpartum dairy cattle', Journal of Dairy Science, vol. 89, pp. 260-66.

Nocek, JE, Kautz, WP, Leedle, JAZ \& Block, E 2003, 'Direct-fed microbial supplementation on the performance of dairy cattle during the transition period', Journal of Dairy Science, vol. 86, pp. 331-35.

NRC 2001, N Nutrient Requirements of Dairy Cattle', 7th ed, National Academy of Science, Washington, DC.

Official Methods of Analysis 2012, 19th edn, AOAC International, Gaithersburg.

Owens, FN, Secrist, DS, Hill, WJ \& Gill, DR 1998, 'Acidosis in cattle: a review', Journal of Animal Science, vol. 76, pp. 275-86.

Pacheco, GFE, Saad, FMDOB \& Trevizan, L 2013, 'Aspectos éticos no uso de animais de produção em experimentação científica', Acta Veterinaria Brasilica, vol. 6, pp. 260-66.

Philippeau, C, Lettat, A, Martin, C, Silberberg, M, Morgavi, DP, Ferlay, A, Berger, C \& Nozière, P 2017, 'Effects of bacterial direct-fed microbials on ruminal characteristics, methane emission, and milk fatty acid composition in cows fed high-or low-starch diets', Journal of Dairy Science, vol. 100 pp. 2637-50.

Raeth-Knight, ML, Linn, JG \& Jung, HG 2007, 'Effect of direct-fed microbials on performance, diet digestibility, and rumen characteristics of Holstein dairy cows', Journal of Dairy Science, vol. 90, pp. 1802-09. Salvati, GGS, Júnior, NM, Melo, ACS, Vilela, RR, Cardoso, FF, Aronovich, M, Pereira, RAN \& Pereira, MN 2015, 'Response of lactating 
cows to live yeast supplementation during summer', Journal of Dairy Science, vol. 98, pp. 4062-73.

Schneider, PL, Beede, DK, Wilcox, CJ \& Collier, RJ 1984, 'Influence of Dietary Sodium and Potassium Bicarbonate and Total Potassium on Heat-Stressed Lactating Dairy Cows', Journal of Dairy Science, vol. 67, pp. 2546-53.

Soriani, N, Panella, G \& Calamari, LUIGI 2013, 'Rumination time during the summer season and its relationships with metabolic conditions and milk production', Journal of Dairy Science, vol. 96, pp. 5082-94.

Swartz, DL, Muller, LD, Rogers, GW \& Varga, GA 1994, 'Effect of yeast cultures on performance of lactating dairy cows: A field study', Journal of Dairy Science, vol. 77, pp. 3073-80.

User's Guide: Statistics 2001, Version 9.01, SAS Institute Inc, Cary, NC. Uyeno, Y, Akiyama, K, Hasunuma, T, Yamamoto, H, Yokokawa, H, Yamaguchi, T, Kawashima, K, Itoh, M, Kushibiki, S \& Hirako, M 2017,
'Effects of supplementing an active dry yeast product on rumen microbial community composition and on subsequent rumen fermentation of lactating cows in the mid-to-late lactation period', Animal Science Journal, vol. 88, pp. 119-24.

Van Soest, PV, Robertson, JB \& Lewis, BA 1991, 'Methods for dietary fiber, neutral detergent fiber, and nonstarch polysaccharides in relation to animal nutrition'. Journal of Dairy Science, v. 74, pp. 3583-97.

Wildman, EE, Jones, GM, Wagner, PE, Boman, RL, Troutt, HF \& Lesch, TN 1982, 'A dairy cow body condition scoring system and its relationship to selected production characteristics', Journal of Dairy Science, vol. 65, pp. 495-501.

Wohlt, JE, Corcione, TT \& Zajac, PK 1998, 'Effect of Yeast on Feed Intake and Performance of Cows Fed Diets Based on Corn Silage During Early Lactation', Journal of Dairy Science, vol. 81, pp. 1345-52. 